\title{
Plan and Reproduction of Multi Input DC-DC Buck Converter for Coordinated Inexhaustible Vitality Produced System Using Fluffy (Fuzzy) Controller.
}

\author{
Shahid.Lingasur ${ }^{1}$ \\ ${ }^{1}$ Lecturer in Dept of Computer Science \\ Government Tool Room and Training Centre \\ Kudalasangama-587118,Karnataka, India \\ E-mail: shahidlingasur@gmail.com
}

\begin{abstract}
The target of this paper is to propose a Multi-input control converter for the cross breed framework so as to disentangle the power framework and lessen the expense. Sustainable power source advancements offers perfect, rich vitality accumulated from self re-establishing assets, for example, the sun, wind and so forth. As the power request expands, control disappointment additionally increments. Along these lines, sustainable power sources can be utilized to give steady loads. Another converter topology for half breed wind/photovoltaic vitality framework is proposed. Hybridizing sun oriented and wind control sources give a practical type of intensity age. The topology utilizes a combination of Buck converters. This design enables the two sources to supply the heap independently or at the same time contingent upon the accessibility of the vitality sources. Reproduction is done in MATLAB/SIMULINK programming and the consequences of the Buck converter and the hybridized converter are introduced.
\end{abstract}

Keywords-Renewable energy, Buck converter, Fuzzy controller,

$* * * * *$

\section{INTRODUCTION}

The energy consumption of the world is increasing dramatically with the rapid increase of population. Renewable energy resources are holding the predominant place for satisfying the future energy demand. Among the available renewable sources, wind and solar are predominant ones, since they have more advantages on production, maintenance, etc, when compared with others. However, the renewable energy generation has a drawback that the change of the output characteristic becomes intense because the output greatly depends on climatic conditions, including solar irradiance, wind speed, temperature, and so forth. Many researches are still going on this field to improve the efficiency of this type of systems having wind and solar as resources. Batteries are usually taken as storage mechanism for smoothing output power, improving startup transitions and dynamic characteristics, and enhancing the peak power capacity. Combining the photovoltaic generation with wind power generation, the instability of an output characteristic each other was compensated. Combining such energy source introduces a PV/WIND/battery hybrid power system.

India is blessed with high solar insulation, already a leader in wind power generation thus hybrid PV/Wind is an ideal combination for power generation in India. According to the 2011 report by GTM Research and Bridge, India is facing a perfect storm of factors that will drive solar photovoltaic (PV) adoption at a "furious pace over the next five years and beyond". As energy demands around the world is on continuous increase, the need for renewable energy sources that will not harm the environment has been increased. Projections indicate that the global energy demand will almost triple by 2050. The role of new and renewable energy resources in power generation is, as of date, very low, but wind energy contribution is increasing significantly in the recent years due to growing energy demand with minimum environmental effect. Renewable energy sources currently supply between $15 \%$ and $20 \%$ of total world energy demand. PV and Wind Energy Systems (WES) are the most promising sources for the future energy technology. A $30 \%$ contribution to world energy will be supplied by renewable energy sources by 2020, which would reduce the energy related $\mathrm{CO} 2$ emission by $25 \%$.

Wind and Solar are complementary, so hybrid Wind/PV power system is an ideal solution for power supply at remote places. Due to the uncertainty in climatic conditions, isolated PV energy system or wind energy system cannot provide a continuous and reliable power supply. In this perspective, to ensure continuous power, installation of battery bank is necessary. Hybrid Wind/PV system is more consistent and economical when compared to two sources considered separately. This further reduces the overall cost and battery storage requirements. With the development of power electronics there is significant growth in solar-wind application with optimization in the size of the system. Usually sunny days are silent and wind speed is rapid at night and at cloudy days, thus hybrid Wind-solar can eliminate the intermittency of single energy source. Another alternative is to provide battery supply to get constant power 
with maximum power tracking from both $\mathrm{PV}$ and wind energy system.

In comparison with single-sourced systems, the hybrid power system has the potential to provide high quality, more reliable, and efficient power. In these systems with a storage element, the bidirectional power flow capability is a key feature at the storage port. Further, the input power sources should have the ability of supplying the load individually and simultaneously. Many hybrid power systems with various power electronic converters have been proposed in the literature up to now. However, the main short comings of these integrating methods are complex system topology, high count of devices, high power losses, expensive cost, and large size. In this work multiple input dc-dc converters is used for combining several energy sources whose power capacity or voltage levels are different. Multi-input dc-dc converter has the capability of operating in different converter topologies (buck, boost, and buck-boost) in addition to its bidirectional operation and positive output voltage without any additional transformer.

\section{PROPOSED SYSTEM}

The objective of the proposed work is to propose a novel multiple input power converters for the grid connected hybrid renewable energy system in order to simplify the power system and reduce cost. The proposed multiple input power converters consists of multiple input DC-DC converter and a full bridge DC-AC inverter.

The proposed work focuses on modeling of photovoltaic, wind hybrid electric power system.

PV and Wind are used as primary sources and battery acts as backup supply.

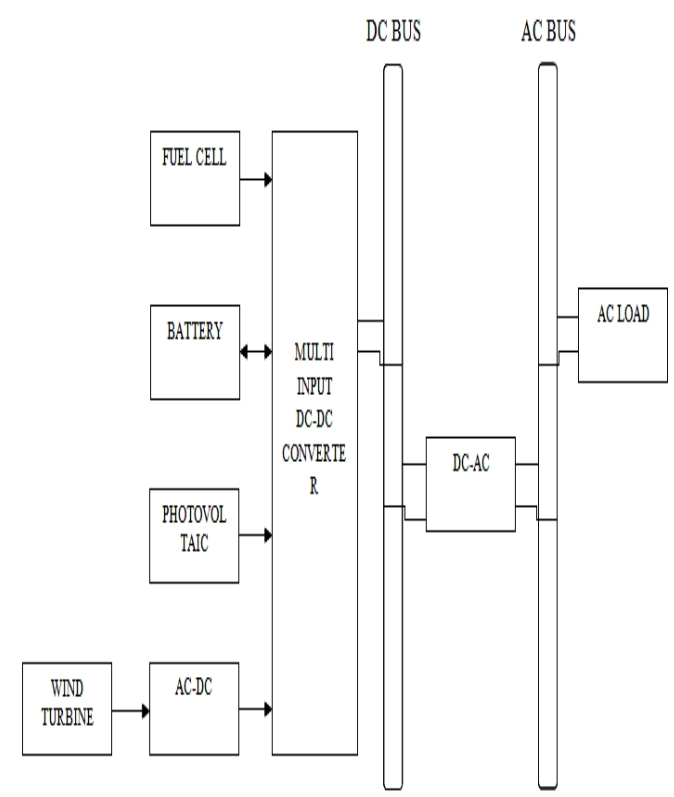

Fig 2.1 shows proposed integrated renewable energy system.
The main aim of proposed work includes selection of appropriate topologies of three phase inverter/rectifier, multiple input DC-DC converter and their control schemes, design and simulation of proposed system and comparison of conventional system with proposed system.

\section{PROPOSED TOPOLOGY}

Double-input buck-buck converter shown in fig. 3 consists of two switches and two diodes. Switching pattern of switches $\mathrm{S} 1$ and $\mathrm{S} 5$ of the conveter are shown in fig.2.1.

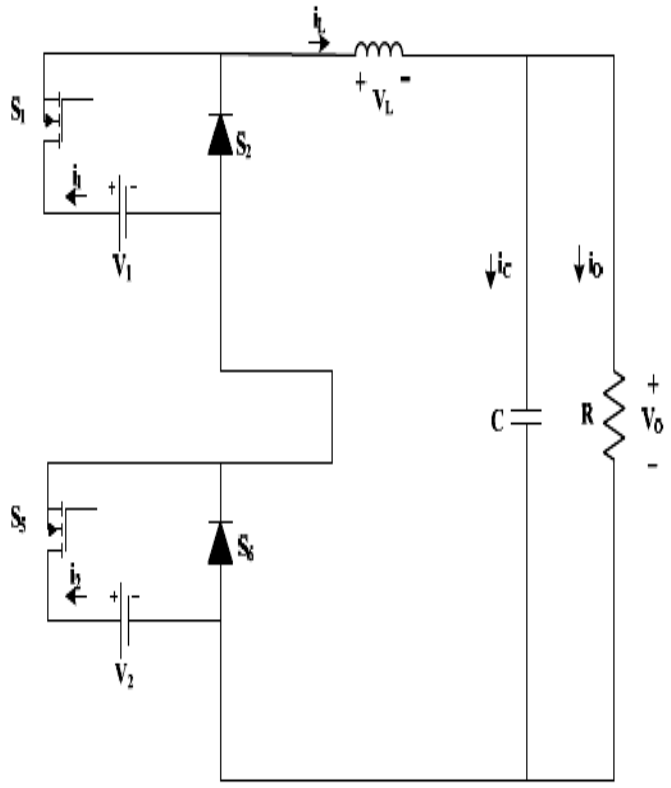

Fig.3 Double-input BUCK-BUCK converter.

The pattern is true for all the possible arrangements of the converter as it consist of all the four modes. Table1.shows the voltage across inductor for different modes of operation of the circuit.

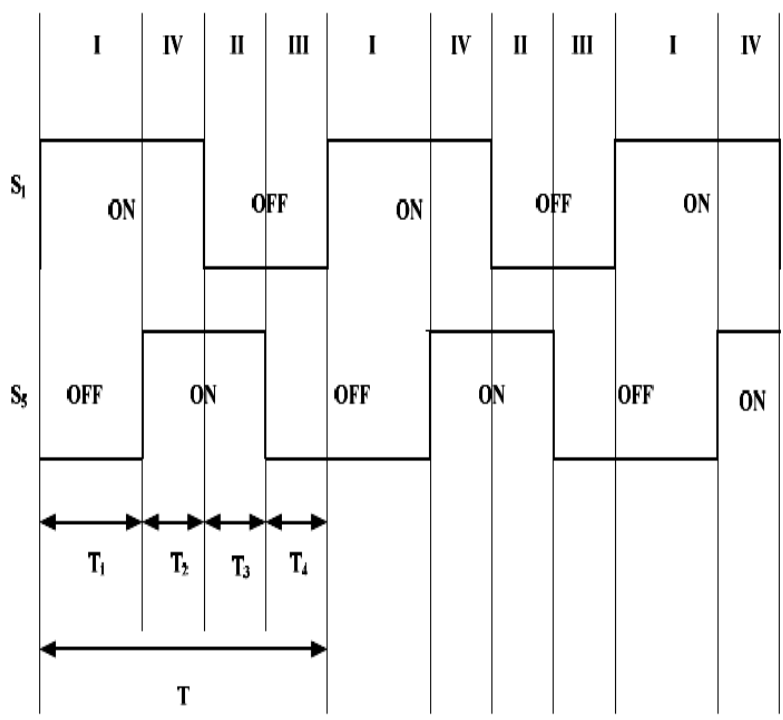

Fig.3.1 Switching pattern of BUCK-BUCK double input $D C-D C$ converter. 
One can see from fig.3.1 that the sum of T1 and T2 is the on time of switch $\mathrm{S} 1$ and sum of $\mathrm{T} 2$ and $\mathrm{T} 3$ is the is the on time of switch S5. Duty cycle is defined as the ratio of switch on time to the period.

\section{$\mathrm{T} 1+\mathrm{T} 2=\mathrm{d} 1 * \mathrm{~T}$}

\section{$\mathrm{T} 2+\mathrm{T} 3=\mathrm{d} 2 * \mathrm{~T}$}

$\mathrm{T}$ is the time period of the switching pattern of $\mathrm{S} 1$ or S5, and $\mathrm{d} 1$ and $\mathrm{d} 2$ are the duty cycles of switches S1 and S5 respectively. One can write the following equations based on the fig.3.1, Table 1 and volt-second balance equation of inductor.

\section{$\mathrm{T} 1+\mathrm{T} 2+\mathrm{T} 3+\mathrm{T} 4=\mathrm{T}$}

$\mathrm{T} 1 *(\mathrm{~V} 1-\mathrm{V} 0)+\mathrm{T} 2 *(\mathrm{~V} 1+\mathrm{V} 2-\mathrm{V} 0)+\mathrm{T} 3 *(\mathrm{~V} 2-\mathrm{V} 0)+$

$\mathrm{T} 4 *(-\mathrm{V0})=0$

\section{This can be simplified as the following equation} $\mathrm{V} 1 *(\mathrm{~T} 1+\mathrm{T} 2)+\mathrm{V} 2 *(\mathrm{~T} 2+\mathrm{T} 3)=\mathrm{V} 0 *(\mathrm{~T} 1+\mathrm{T} 2+\mathrm{T} 3+\mathrm{T} 4)$

Combining equations (1),(2),and (5) one can obtain the following equation which gives the relation between input and output.

\section{$V 1 * d 1+V 2 * d 2=V 0 * 1$ \\ $V 0=d 1 * V 1+d 2 * V 2$}

Equation (6) determines the transfer function of the doubleinput buck-buck dc-dc converter. It can also be observed that the output is positive as long as the two sources are positive. 1

Table.1 Voltage across the inductor for different modes of operation of BUCK-BUCK converters.

\begin{tabular}{|l|l|l|l|l|}
\hline & $\mathbf{T}_{1}$ & $\mathbf{T}_{2}$ & $\mathbf{T}_{3}$ & $\mathbf{T}_{4}$ \\
\hline $\mathbf{S}_{1}$ & ON & ON & OFF & OFF \\
\hline $\mathbf{S}_{5}$ & OFF & ON & ON & OFF \\
\hline $\mathbf{V}_{\mathrm{L}}$ & $\mathbf{V}_{1}-\mathbf{V}_{0}$ & $\mathbf{V}_{1}+\mathbf{V}_{2}-\mathbf{V}_{0}$ & $\mathbf{V}_{2}-\mathbf{V}_{0}$ & $-\mathbf{V}_{0}$ \\
& & & & \\
& & & & \\
\hline
\end{tabular}

Table.2 Transferfunction ratio of double input DCDCconverter.

\begin{tabular}{|l|l|l|}
\hline $\begin{array}{l}\text { Double-input } \\
\text { converter } \\
\text { topology }\end{array}$ & $\begin{array}{l}\text { Voltage transfer } \\
\text { ratio }\end{array}$ & Range of v0 \\
\hline Buck-Buck & $\mathbf{V}_{0}=\mathbf{d}_{1} * \mathbf{v}_{1}+\mathbf{d}_{2} * \mathbf{v}_{2}$ & $0<\mathrm{v}_{0}<\mathbf{v}_{1}+\mathbf{v}_{2}$ \\
& & \\
\hline
\end{tabular}

\section{FUZZY CONTROLLER}

Traditionally, PD, PI and PID controller are most popular controllers and they are widely used in most power electronic closed loop appliances, But in the recent year there are many researchers reported successfully adopted the Fuzzy Logic Controller (FLC) to become one of intelligent controllers. This work focuses on using fuzzy logic controller with feedback of voltage output respectively. The voltage output in the circuit will be fed to fuzzy controller to give appropriate measure on steady state signal. This technique can be applied to many dc-dc converter topologies such as Buck, Boost and Buck-Boost.

Based on the human knowledge fuzzy logic control is built up by a group of rules of system behavior. For the dynamic behavior of dc-to-dc converter and performance of proposed controllers we use MATLAB simulation. The design of fuzzy logic controller can provide desirable both large signal and small signal dynamic performance, which is not possible in linear control technique. Thus, fuzzy logic controller has an ability to improve the robustness of dc-todc converters.

The basic scheme of the controller consists of four principal components such as a Fuzzification, which converts input data value into suitable linguistic values a knowledge base, which consists of control rule set and a data base with the necessary linguistic definitions a Decision-Making logic, which is use to simulating a human decision process and infer the fuzzy control action from the knowledge of the control rules and linguistic variable definitions. And a Defuzzification interface, which yields non fuzzy control action from an inferred fuzzy control action.

\section{Fuzzy Logic Membership Function}

The dc-dc converter is a nonlinear function of the duty cycle because of the small signal model and its control method was applied to the control of buck converters. In Fuzzy controllers mathematical model is not require. Instead, they are designed based on general knowledge of the plant (converter). The Fuzzy controllers are designed to adopt the varying operating points. Fuzzy Logic Controller is 
designed to control the output of dc-dc converter. In the fuzzy logic system two input variables, error (e) and change of error (de) and one output variable (u) is duty cycle of PWM output are used. For each input and output variable fuzzy sets must be defined. The five fuzzy subsets PS (Positive Small), PB (Positive Big), ZE (Zero), NS (Negative Small), NB (Negative Big) has been chosen for input variables error (e) and change of error (de). The Triangular shape has been adopted for the membership functions; the value of each input and output variable is normalized in the range $[-1,1]$ by using suitable scale factors.

\section{Fuzzy Logic Table Rules}

Fuzzy controller rules which are playing a very important role for controller simulation are obtained from the analysis of the system behavior. In their formulation it must be considered that, by using this controller we improve the converter performances in terms of dynamic response and robustness. when the output voltage is far from the set point i.e. error(e) is NB or PB, the controller must be do the strong corrective action i.e. duty cycle close to zero or have the dynamic response as fast as possible, obviously taking into account current limit specifications of the system.

Second, when output voltage error of the system approaches to zero i.e. error (e) is ZE, NS, PS then in order to ensure stability around the working point, the current error should be properly taken into account. When the current value approaches the limit value, suitable rules must be introduced to preventing the large overshoots.

\section{SIMULATION RESULTS}

Figure 5.1 shows the typical simulation results of the buckbuck converter using MATLAB/Simulink. Two dc voltage sources $\mathrm{V}_{1}=100 \mathrm{~V}$ and $\mathrm{V}_{2}=150 \mathrm{~V}$ are used for the input voltage sources. The switching commands for $S_{1}$ and $S_{5}$ have fixed duty ratio of 0.5 at the switching frequency of $100 \mathrm{KHz}$. From top to bottom are the waveforms of load voltage and load current, switching commands $S_{1}$ and $S_{5}$, capacitor voltage $\mathrm{V}_{\mathrm{c}}$. one can observe from the waveforms that the average value of output voltage is arround $125 \mathrm{~V}$ which can also be obtained from the transfer function of table2.

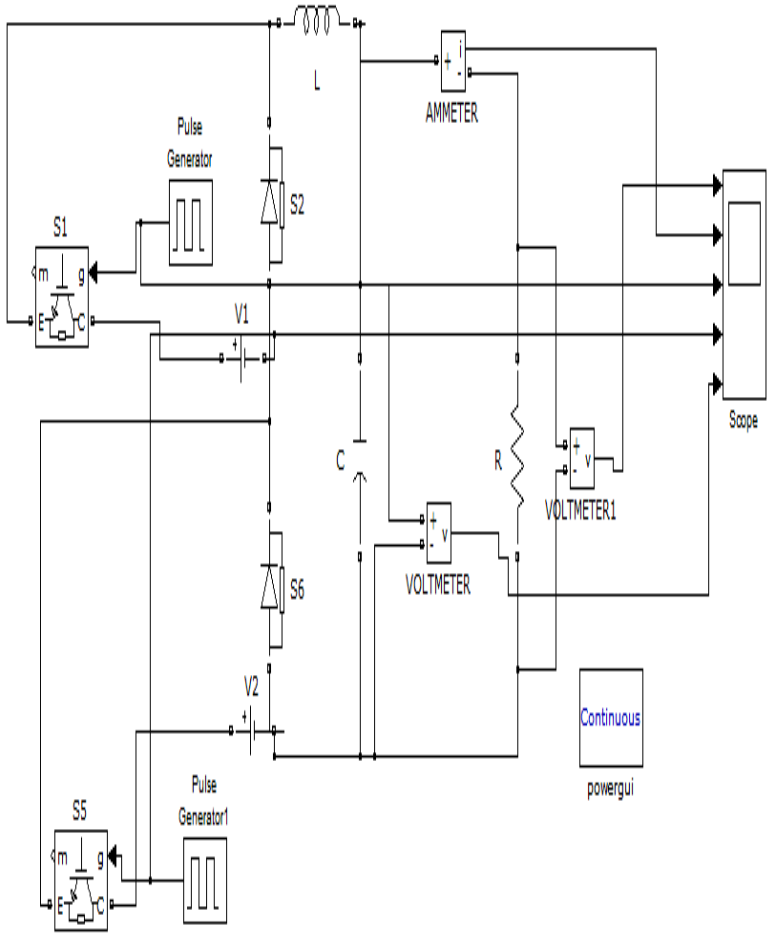

Fig.5 Simulation of double-input buck-buck converter using MATLAB/Simulink.

\section{Load voltage and load current.}

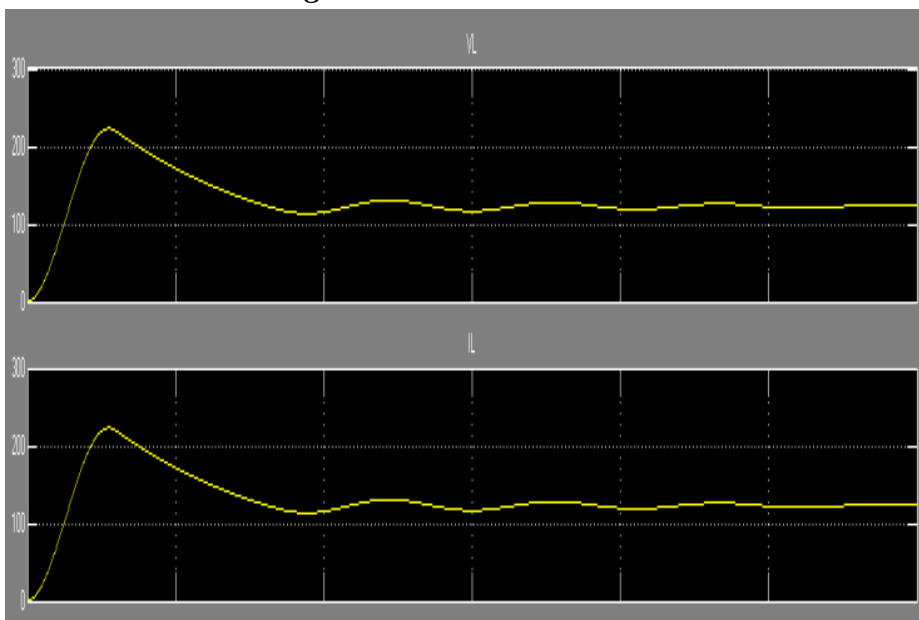

II. Switching commands.

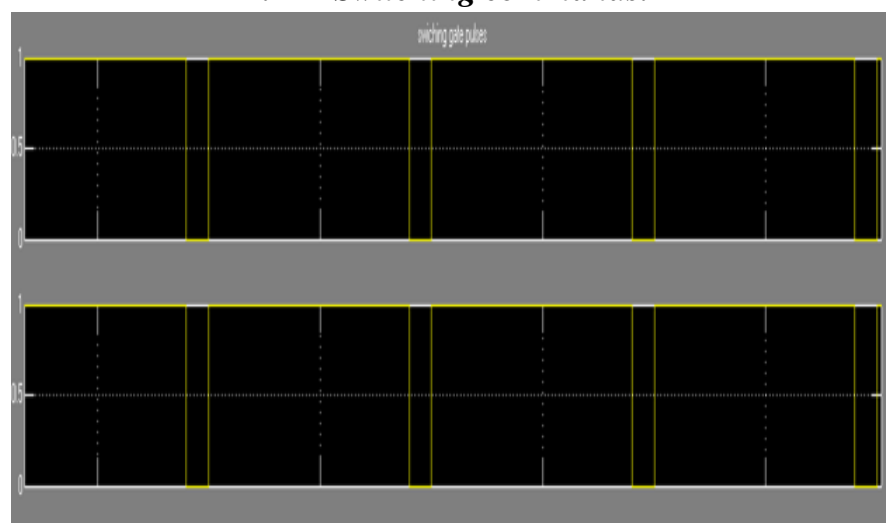




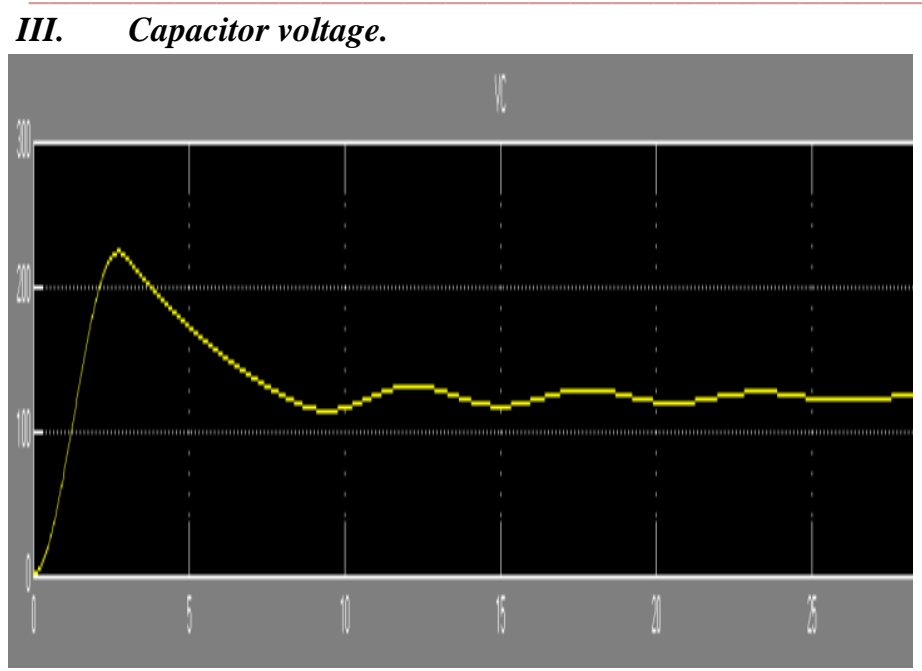

Fig.5.1 Simulation waveforms of double-input buck-buck converter.

Table.3 Output voltage for various duty cycle are presented in the above table

\begin{tabular}{|l|l|l|}
\hline SL NO. & Duty ratio & Output voltage \\
\hline 1 & 0.2 & $50 \mathrm{~V}$ \\
\hline 2 & 0.4 & $100 \mathrm{~V}$ \\
\hline 3 & 0.6 & $150 \mathrm{~V}$ \\
\hline 4 & 0.8 & $200 \mathrm{~V}$ \\
\hline
\end{tabular}

\section{SIMULATION RESULTS USING FUZZY CONTROLLER}

Fig 5.1 shows the typical simulation results of the buckbuck converters using Fuzzy controller. Two dc voltage sources $\mathrm{V} 1=200 \mathrm{~V}$ and $\mathrm{V} 2=250 \mathrm{~V}$ are used for the input voltage sources. The switching commands for S1 and S5 have duty ratio and switching frequency set by the fuzzy controller. From top to bottom are the waveforms of load voltage and load current, switching commands S1 and S5, capacitor voltage Vc. One can observe from the waveforms that the average value of output voltage is obtained as we required.

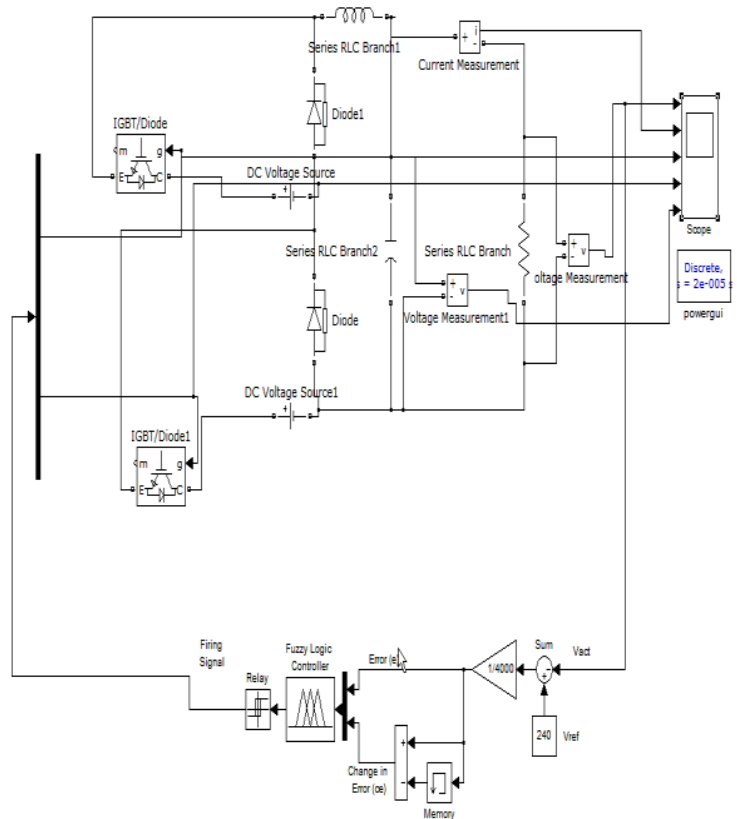

Fig 5 Simulation of double-input buck-buck converter using fuzzy controller.

Table. 4 Rule table for buck converter

\begin{tabular}{|l|l|l|l|l|l|l|l|}
\hline $\begin{array}{l}\text { ce } \\
\boldsymbol{N}\end{array}$ & $\boldsymbol{N B}$ & $\boldsymbol{N M}$ & $\boldsymbol{N S}$ & $\boldsymbol{Z E}$ & $\boldsymbol{P S}$ & $\boldsymbol{P M}$ & $\boldsymbol{P B}$ \\
\hline $\boldsymbol{N B}$ & $P B$ & $P B$ & $P B$ & $P B$ & $P M$ & $P S$ & $Z E$ \\
\hline $\boldsymbol{N M}$ & $P B$ & $P B$ & $P B$ & $P M$ & $P S$ & $Z E$ & $N S$ \\
\hline $\boldsymbol{N S}$ & $N B$ & $N B$ & $N M$ & $N S$ & $Z E$ & $P S$ & $P M$ \\
\hline $\boldsymbol{Z E}$ & $N B$ & $N M$ & $N S$ & $Z E$ & $P S$ & $P M$ & $P B$ \\
\hline $\boldsymbol{P S}$ & $N M$ & $N S$ & $Z E$ & $P S$ & $P M$ & $P B$ & $P B$ \\
\hline $\boldsymbol{P M}$ & $N S$ & $Z E$ & $P S$ & $P M$ & $P B$ & $P B$ & $P B$ \\
\hline $\boldsymbol{P B}$ & $Z E$ & $P S$ & $P M$ & $P B$ & $P B$ & $P B$ & $P B$ \\
\hline
\end{tabular}

\section{Load voltage and load current.}

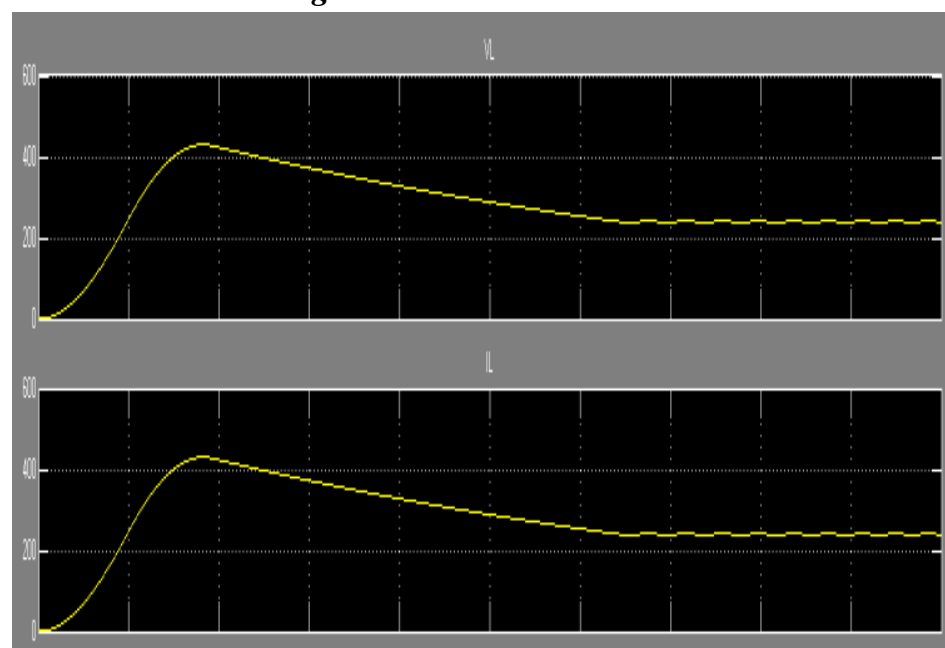




\section{Switching commands.}

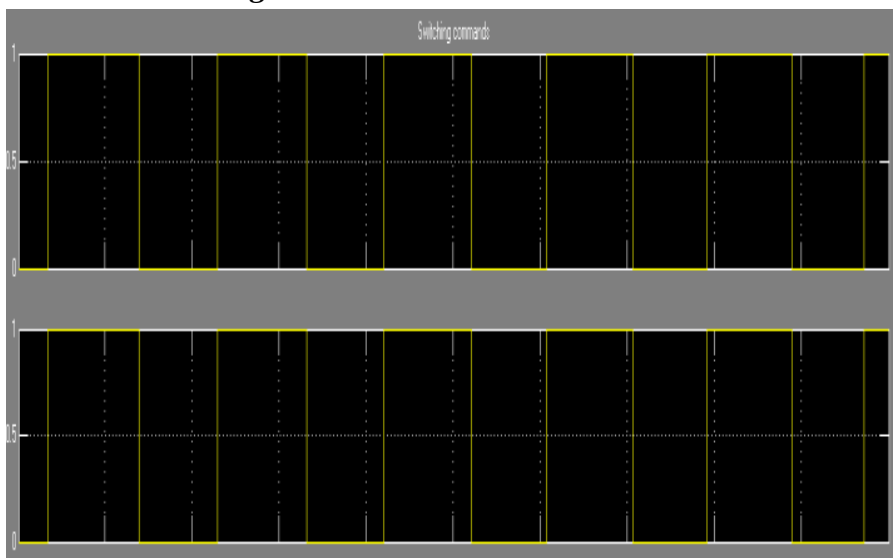

\section{Capacitor voltage.}

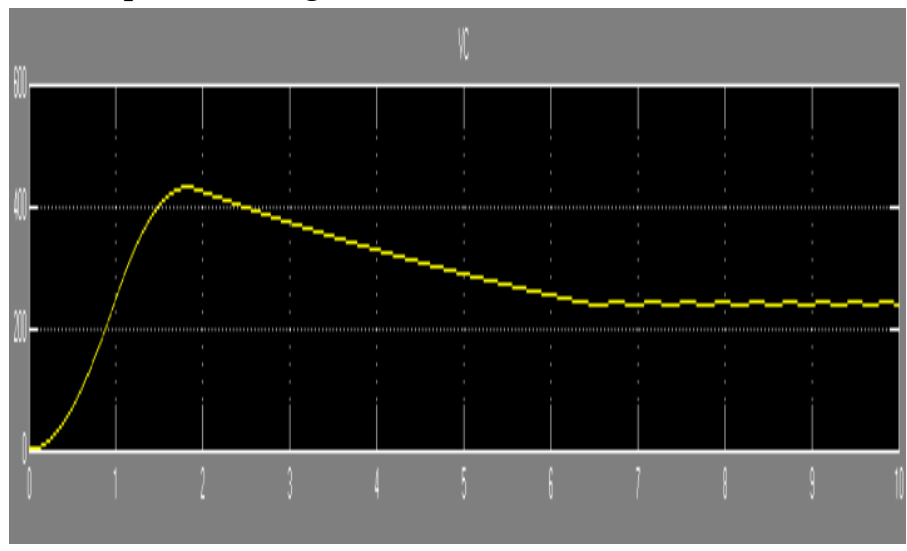

Fig.5.1 Simulation waveforms of double-input buck-buck converter using fuzzy controller.

Table. 5 Output voltage for various reference voltages are presented in the below table

\begin{tabular}{|c|c|c|}
\hline SL NO. & $\begin{array}{c}\text { Reference output } \\
\text { voltage } \\
\text { set }\end{array}$ & $\begin{array}{c}\text { Simulated Output } \\
\text { voltage } \\
\text { obtained }\end{array}$ \\
\hline 1 & 125 & 124.6 \\
\hline 2 & 175 & 174.5 \\
\hline 3 & 220 & 219 \\
\hline 4 & 380 & 378 \\
\hline
\end{tabular}

\section{CONCLUSION}

In this paper, the operation principle of the proposed multiinput dc-dc converter has presented. The multiple input DCDC buck converter circuit is designed and simulated using MATLAB/Simulink software. Simulation results are shown here to verify the performance of the proposed multi-input dc-dc converter system with the desired features. From the results acquired during the simulation, it was confirmed that with a well designed system including a proper converter and selecting an efficient controller, it is simple and can be easily constructed to achieve an acceptable efficiency level of the PV modules and wind turbine.

\section{REFERENCES}

[1]. J. L. Duarte, M. Hendrix, and M. G. Simoes, "Three-port bidirectional converter for hybrid fuel cell systems," IEEE Trans. Power Electron., vol. 22, No. 2, Mar. 2007.

[2]. K. Rajashekara, "Hybrid fuel-cell strategies for clean power generation," IEEE Trans. Ind. Appl., vol. 41, No. 3,June 2008.

[3]. F. Valenciaga and P. F. Puleston, "Supervisor control for a stand-alone hybrid generation system using wind and photovoltaic energy," IEEE Trans. Energy Conversion, vol. 20, June 2009.

[4]. J. M. Carrasco, L. G. Franquelo, J. T. Bialasiewicz, E. Galvan, R. C. PortilloGuisado, M. A. M. Prats, J. I. Leon, and N.Moreno-Alfonso, "Power-electronic systems for the grid integration of renewable energy sources: A survey," IEEE Trans. Ind. Electron., vol. 53, No. 4, June . 2009.

[5]. K. N. Reddy and V. Agrawal, "Utility-interactive hybrid distributed generation scheme with compensation feature," IEEE Trans. Energy Convers., vol. 22, No. 3, Sep. 2010.

[6]. H. Tao, J. L. Duarte, and M. A.M. Hendrix, "Three-port triple-half-bridge bidirectional converter with zero-voltage switching," IEEE Trans. Power Electron., vol. 23, No. 2, Mar. 2010.

[7]. O. C. Onara,M. Uzunoglu, andM. S. Alam, "Modeling, control and simulation of an autonomous wind turbine/photovoltaic/fuel cell/ultra capacitor hybrid power system,” J. Power Sources., vol. 185, No. 2, Apr.2011.

[8]. A. Khaligh, J. Cao, and Y. J. Lee, "A multiple-input DCDC converter topology," IEEE Trans. Power Electron., vol. 24, no. 3, Mar. 2011.

[9]. S. H. Hosseini, S. Danyali, F. Nejabatkhah, and S. A. K. Mozafari Niapour, "Multi-input DC boost converter for grid connected hybrid PV/FC/battery power system," in Proc. IEEE Elect. Power Energy Conf., 2012

[10].R. J. Wai, Ch. Y. Lin, J. J. Liaw, and Y. R. Chang, "Newly designed ZVS multi-input converter," IEEE Trans. Ind. Electron., vol. 58, No. 2, Feb. 2013

[11].Farzam Nejabatkhah, Saeed Danyali, Seyed Hossein Hosseini,Mehran Sabahi, and Seyedabdolkhalegh Mozaffari Niapour, "Modeling and Control of a New Three-Input DC-DCBoost Converter for Hybrid PV/FC/Battery Power System" IEEE Trans . Power Electron., vol.27, NO. 5, May 2013.

[12].K.V.Hari Prasad ; Second CH.Uma Maheswar Rao; Third A.Sri Hari; Dept. of Electrical Engineering, Vignan University, "Design and simulation of a fuzzy logic controller for buck \& boost converters". International journal of advanced technology \& engineering research (IJATER)

[13].Rajesh Kr Ahuja, Rajesh Kumar,Department of Electrical Engineering, YMCA University of Sciences \& Technology, "Design and Simulation of Fuzzy Logic Controller based Switched-Mode Power Supply", IPASJ International Journal of Electrical Engineering (IIJEE) Web Site: http://www.ipasj.org/IIJEE/IIJEE.htm. 